\title{
The potential of pharmacological
} activities of the multi-compound treatment for GERD: literature review and a network pharmacology-based analysis

Junghyun Park ${ }^{1,2 \dagger}$, Dongyeop Jang ${ }^{1 \dagger}$, Hung Manh Phung ${ }^{1}$, Tae Joon Choi ${ }^{2,3}$, Chang-Eop Kim ${ }^{1}$, Sanghyun Lee ${ }^{4}$, Ki Sung Kang ${ }^{1 *}$ and Seo-Hyung Choi ${ }^{5^{*}}$ (i)

\begin{abstract}
The prevalence of gastroesophageal reflux disease (GERD) is rapidly increasing due to the adoption of a Westernized lifestyle; at the same time, safe and efficient treatment is required due to the side effects and refractoriness of proton pump inhibitors (PPIs). The frequently used multi-compound treatment for GERD in the current traditional Korean medicine (TKM) clinical field comprises Crassostrea gigas Thunberg shell (CGTS), Bambusae Caulis in Taeniam (BCT), Ponciri Fructus Immaturus (PFI), Scutellaria baicalensis Georgi (SBG), medicated leaven (ML) and Glycyrrhizae Radix et Rhizoma (GRR). The current review was based on "Kun-Shin-Choa-Sa" theory and network analysis was conducted to explore the potential pharmacological activities, including efficacy and mechanisms of action of multi-compound treatment against GERD. Hypergeometric test results showed that the targets of multi-compound treatment are significantly associated with GERD gene sets, consistent with the literature review findings. In particular, the enrichment analysis indicated that the SBG targets are related to the IL-17 signaling pathway, bile secretion, small-cell lung cancer, and non-small cell lung cancer, corroborating the literature review, particularly concerning anti-inflammatory effect. In the literature review, CGTS and BCT, classified as "Kun," play a role in anti-acid, anti-inflammatory, and anti-oxidative effects. The complementary "Shin" herbs, PFI and SBG, showed functions related to improving the prolonged gastric emptying rate, peristalsis, and a gastric cytoprotective effect. With the role of "Choa," ML was suggested to inhibit $H$. pylori growth and diminish gastric acid secretion, consistent with the gastric acid secretion pathway in the enrichment analysis. However, the enrichment analysis did not show any significantly related pathways for CGTS and PFI, which may reflect the lack of information in the KEGG database in terms of the link between GERD, its mechanisms, and the abundance of minerals in CGTS. Despite the pharmacological potential of multi-compound treatment, this study should be corroborated by well-designed future experimental studies.
\end{abstract}

Keywords: GERD, Multi-compound treatment for GERD, Network pharmacological analysis, "Kun-Shin-Choa-Sa” theory

*Correspondence: kkang@gachon.ac.kr; woojeim9212@gmail.com †Junghyun Park and Dongyeop Jang contributed equally to this study ${ }^{1}$ College of Korean Medicine, Gachon University, Seongnam 13120, Republic of Korea

${ }^{5}$ Department of Oriental Internal Medicine, Gangnam Weedahm Oriental Hospital, Seoul 06185, Republic of Korea

Full list of author information is available at the end of the article

\section{Introduction}

The prevalence of gastroesophageal reflux disease (GERD) in the Western countries is relatively high, ranging from 10 to $20 \%$ [1]. The 2008 GERD prevalence in South Korea was $3.5-8.5 \%$, which is lower than that in the West [2-4]. However, the recent prevalence in South Korea has been increasing due to the westernization of 
dietary lifestyle, an increase in the obese population, and rapid growth in the elderly population [5]. To ease recurrent severe symptoms that lower patient quality of life, safe and effective GERD therapy is required. Ranitidine and proton pump inhibitors (PPIs) are medications that decrease stomach acid production and are commonly used to treat peptic ulcer disease and GERD. Recently, the United States Food and Drug Administration announced the decision to withdraw all prescription and over-the-counter (OTC) ranitidine drugs from the market. Although the prescription of PPI drugs is increasing rapidly due to the "carcinogenic" concerns surrounding ranitidine, experts are warning against the long-term use of PPI drugs, which may cause more severe side effects than ranitidine [6]. Therefore, there is an increasing interest in complementary and alternative medicine (CAM) with synergistic effects and fewer side effects.

In Korea, traditional Korean medicine (TKM) practitioners can legally allowed to prescribe herbal medicines according to the pattern differentiation of traditional East Asian medicine (TEAM) for patients by combining herbs that have been used for a long time. TKM practitioners diagnose and prescribe based on the unique disease classification system of Donguibogam published by Dr. Heo Jun in the Joseon Dynasty (400 years ago) based on the "Kun-Shin-Choa-Sa" theory [7]. Due to their uniqueness and considerable efficacy, the treatments are still widely adopted in the current TKM clinical field. Some of the treatments may not be effective for modern patients due to lifestyle changes including diet and environment. Some established TKM practitioners have their own confidential prescriptions formulated by empirically supported treatment knowledge. In the present study, a frequently used multi-component prescription (P05), for the curative therapy of GERD in the clinical field is reviewed from a pharmacological activity and perspective. Additionally, P05 was analyzed in silico via network analysis to predict and explore the specific targets and pathways for each ingredient as a background for future assessments of P05 efficacy in in vitro, in vivo, and clinical trials.

\section{Study design and methods}

A literature review and network pharmacological analysis were conducted to elucidate the potential pharmacological activities of a multi-compound herbal mixture in GERD treatment.

\section{Search strategy for review}

A search was performed for English and Korean literature in online databases, including PubMed, Google Scholar, and ScienceDirect. Several keywords were used, including "GERD," "GERD treatment," "CAM treatment," "Crassostrea gigas Thunberg shell," "Crassostrea gigas Thunberg shell GERD [or gastrointestinal (GI) diseases]," "Bambusae Caulis in Taeniam," "Bambusae Caulis in Taeniam GERD [or gastrointestinal (GI) diseases]," "Ponciri Fructus Immaturus," " Ponciri Fructus Immaturus GERD [or gastrointestinal (GI) diseases]," "Scutellaria baicalensis Georgi," "Scutellaria baicalensis Georgi GERD [or gastrointestinal (GI) diseases]," "Medicated leaven," "Medicated leaven GERD [or gastrointestinal (GI) diseases]," "Glycyrrhizae Radix et Rhizoma," "Glycyrrhizae Radix et Rhizoma GERD [or gastrointestinal (GI) diseases]."

\section{Network pharmacological analysis}

Network pharmacological analysis was performed by predicting the targets of the ingredients in P05 and constructing a herb-compound-target network. The information on herb compounds was obtained from the TCM-MESH database (http://mesh.tcm.micro bioinformatics.org). "Bambusae Caulis in Taeniam" and "Medicated leaven" were not included in the TCMMESH database; therefore, we obtained their compound information from previous studies that were based on high-performance liquid chromatography $[8,9]$. To filter out compounds that hardly play a drug role in oral administration, we employed the quantitative estimate of drug-likeness (QED) method, which measures druglikeness based on molecular descriptors [10]. QED outperforms other drug-like classifiers, such as the Rule of 5 , Ghose filter, and Veber's rule. The QED ranges from 0 to 1 , and the closer the QED of a compound is to 1 , the more drug-like it is. We set the QED cut-off value for the compounds at 0.35 , as it is the overall average of QED for FDI-approved oral drugs. The potential targets of the compounds were obtained from STITCH (http://stitch. embl.de/) based on the combined scores of interactions between compounds and targets. We set the threshold of the combined score at 0.7 , which is regarded as the criterion for filtering prediction results with high confidence. An herb-compound-target network was then constructed by linking herbs to their compounds, and compounds to their predicted targets using in-house Python (version 3.8) code and visualized using Cytoscape (version 3.8.2). Gene set enrichment analysis (GSEA) based on the Kyoto Encyclopedia of Genes and Genomes (KEGG, https:// www.genome.jp/kegg/), DisGeNET (https://www.disge net.org/search), and Human Phenotype Ontology (HPO, https://hpo.jax.org/) databases was performed to identify the relationship between herbal targets and diseases, and potential pathways associated with GERD using hypergeometric tests and Enrichr [11-14]. We calculated adjusted $\mathrm{p}$-values, and combined scores using the logarithm of the multiplication of the p-values and z-scores 
(note that the combined score differs from the combined score in STITCH).

\section{GERD and its pathophysiology}

GERD is a complex clinical condition whose definition was standardized in 2006 with the Montreal Consensus. The relationship between symptoms and stomach content reflux is complex due to the difficulty distinguishing between GERD and functional esophageal disorders, which requires comprehensive classification [15].

The primary symptoms of GERD contributing to esophageal mucosal injury are heartburn, acid regurgitation, dysphagia, and globus $[16,17]$. GERD is accompanied by a wide range of complications such as erosive esophagitis, esophageal stricture, Barrett's esophagus, and esophageal adenocarcinoma [18]. Understanding the pathophysiology of GERD plays a significant role in exploring future treatment targets, since proton pump inhibitor resistance is a common problem [19]. Multiple factors are involved in the pathogenesis of GERD, including transient lower esophageal sphincter relaxation and other lower esophageal sphincter (LES) pressure abnormalities. Furthermore, hiatal hernia, injured esophageal clearance, prolonged gastric emptying, and impaired mucosal defensive factors are responsible for the pathophysiology of GERD. Hiatal hernia promotes LES dysfunction, and injured esophageal clearance contributes to delayed acid exposure of the mucosa. Prolonged gastric emptying leads to gastric distension, and consequently, postprandial GERD [20]. In addition to the factors mentioned above, increased distensibility of the esophagogastric junction, obesity, and acid pocket, layers of highly acidic gastric secretion, can be risk factors for GERD. Multiple mechanisms have an impact on the perception of GERD symptoms. With regard to the involvement of Helicobacter pylori infection, the relationship is still subject to debate. Meanwhile, it has been reported that $H$. pylori eradication in GI acid production changes is not an important concomitant factor for GERD, according to the Maastricht V/Florence Consensus report [6].

Typically, when food is swallowed, the LES allows food to flow into the stomach and subsequently, tightens again to maintain the stomach content in the stomach via the esophagogastric junction (EGJ) [21]. The EGJ is composed of the smooth muscle of the LES surrounded by oblique gastric fibers and the crural diaphragm acting as an anti-reflux barrier [22]. When LES pressure is lower than the intragastric pressure, reflux occurs. Specifically, the frequency of transient lower esophageal sphincter relaxation (TLESR) is augmented when the intragastric pressure increases.

\section{Treatment for GERD and its shortcomings}

Patients with GERD need appropriate medical care to alleviate the recurrent and refractory symptoms that severely deteriorate their quality of life and burden them with medical expenses. Proton pump inhibitors (PPIs) effectively suppress gastric acid secretion, manage the esophageal mucosa, alleviate GERD symptoms, and prevent complications among the available GERD medications [23]. PPI medications function by irreversibly hindering an $\mathrm{H}$ p/ $\mathrm{K}_{\mathrm{p}}$ adenosine triphosphatase in the stomach's parietal cells, which inhibits hydrogen (protons) from being pumped into the gastric lumen to produce hydrochloric acid. Commonly available PPIs include omeprazole (Prilosec), esomeprazole (Nexium), lansoprazole (Prevacid), dexlansoprazole (Dexilant), pantoprazole (Protonix), and rabeprazole (Aciphex), with omeprazole being the most prescribed among those [21].

Although PPIs have become a major therapy for GERD, approximately $20-40 \%$ of GERD patients do not respond to PPIs $[23,24]$. Refractory GERD is a widespread clinical condition that presents a lack or absence of response after 4-8 weeks of twice-daily PPI treatment [25]. In gastroenterology, refractory GERD is a frequent cause for medical care. Several GERD patients continue to have clinical manifestations despite PPI use.

Furthermore, PPIs have side effects, such as headache, diarrhea, nausea, and vomiting. According to a previous report, PPIs are associated with chronic kidney disease, cardiovascular disease, and gastric, esophageal, and liver cancers. One Washington University-based researcher warned that long-term PPI use over several months or years is unsafe [21]. Nutrient deficiencies as PPI side effects have also been reported, especially of micronutrients, including magnesium, vitamin $\mathrm{B}_{12}$, calcium, iron, and vitamin $C$, whose absorption is negatively affected [26].

Taken together, dietary and lifestyle changes as a behavioral treatment are recommended for GERD patients because these have no side effects, and obesity is a significant risk factor for GERD. In fact, previous research has indicated that a reduced body mass index can lead to a reduction in GERD symptom frequency. In general, losing weight, elevating the head of the bed, avoiding sleeping on the right side of the body, avoiding eating at least three hours before bedtime, avoiding fatty and spicy meals, avoiding excessive eating, etc., are recommended as dietary and lifestyle interventions [21]. However, this is not a fundamental solution for GERD; thus, effective and safe therapy for GERD is still necessary. 


\section{Multi-compound treatment}

\section{and the Kun-Shin-Choa-Sa theory}

It has been reported that the refractoriness and several side effects of long-term PPI use, regarded as the primary treatment, have invariably increased needs for CAM-based natural drugs. Therefore, in clinical practice, several GERD patients turn to TEAM as they experience recurrent GERD symptoms despite PPI treatment [23]. Unlike conventional medications, herbal mixtures in TEAM are based on a multi-component and multitarget approach derived from a holistic philosophy [27]. To deal with complex diseases, multi-component and multi-target approaches are potentially meaningful despite the challenges in elucidating the complex mechanisms involved. Among TEAM, TKM practitioners diagnose according to pattern identification by observing the symptoms and signs exhibited by patients based on Donguibogam written by Dr. Heo Jun in the Joseon Dynasty (400 years ago) [7]. In TEAM, GERD is classified into three different syndromes (patterns), including "Disharmony of Liver and Stomach," referring to the failure of smooth flow of liver qi and stomach qi descending; "Deficiency-Cold of Spleen and Stomach, a part of the digestive system and sources of qi and blood in TEAM," meaning the deficiency of qi and blood and dysfunction of spleen-stomach $[28,29]$.

After diagnosis by defining a phenotype that can guide treatment selection as a unique diagnostic system, TKM practitioners subsequently prescribe using the "KunShin-Choa-Sa" theory translated as "king-minister-assistant-ambassador" for its synergistic effects. In the past, ancient Koreans thought that taking care of the human body is philosophically similar to running a nation. The "Kun" refers to a major medicine possessing the main drug efficacy, which is supported by three different types of medicines: the "Shin" (minister), which boosts and complements the Kun's efficacy; "Choa" (assistant), which reduces the side-effects caused by the "Kun", the "Sa" (ambassador), which facilitates delivery of the "Kun" [30].

A previous study indicated that despite the intrinsic complexity of herbal mixtures, medicinal plants have the advantage of synergistic interactions among their multiple-components and poly-pharmacological effects [27]. Since TKM considers the human body as one, which is a complex interacting system, with each cell, tissue, and organ connected to each other, therapeutic drugs to restore energy and overall body balance are also prescribed by TKM practitioners according to the "Kun-Shin-Choa-Sa" theory. Consequently, it is believed that a single active ingredient or component made for a single target, such as PPIs, can cause severe side effects, as it arbitrarily controls one organically connected part. Here, a multi-component herbal mixture prescribed by
TKM practitioners based on the "Kun-Shin-Choa-Sa" principle using medicinal plants that have been used for a long time is presented. The frequently used multi-compound herbal medicine, P05, has been modified for modern GERD patients based on 30 years of knowledge. P05 comprises a basic composition for GERD therapy and other specific herbs. Six P05 ingredients can be added according to specific symptoms and signs since TKM is an individualized treatment for different patients with the same disease $[29,31]$.

The herbal mixture (P05) consists of Crassostrea gigas Thunberg shell (CGTS), Bambusae Caulis in Taeniam (BCT), Ponciri Fructus Immaturus (PFI), Scutellaria baicalensis Georgi (SBG), medicated leaven (ML) and Glycyrrhizae Radix et Rhizoma (GRR). Among the complex P05 components, CGTS and BCT play the role of "Kun", while the roles of "Shin", "Choa", and "Sa" are played by PFI and SBG, ML, and GRR, (Fig. 1).

The bioactive components of P05 for GERD treatment are presented in Table 1. Previous reports have shown that P05 can improve GERD symptoms through antiinflammation, apoptosis modulation, hormone levels regulation, antioxidant activity, acid suppression, pepsin secretion reduction, and mucosal protection.

\section{Crassostrea gigas Thunberg shell as one of "Kun-Kings"}

Oysters shell, Ostreae Concha/Crassostrea gigas Thunberg shell (CGTS), has been commonly used with other herbs in TEAM prescriptions to alleviate diverse symptoms, including abdominal mass, tinnitus, insomnia, dizziness, palpitations, scrofula, and subcutaneous nodules. It has been reported that immune system reinforcement, anti-acid, anti-gastric ulcer, sedation, anti-tumor, and anti-virus properties are among the pharmacological effects of oyster shell [32]. Calcium carbonate (more than 95\% content) and calcium phosphate have been confirmed to be representative components of oyster shell. Oyster shell has been widely used as a primary ingredient in calcium supplements, pharmaceuticals, and animal feed, owing to its calcium carbonate content. Taurine and betaine have been reported as components of oyster muscle blocks in oyster shell. Various biological functions of taurine, such as bile acid conjugation, antioxidation, membrane stabilization, and modulation of calcium signaling, have been reported. Taurine and betaine are known to improve diabetes and have lipid-lowering effects [33]. Additionally, calcium sulfate and proteins such as conchiolin are CGTS components, and the anti-inflammatory effect of CGTS extract has been reported [34, 35].

\section{Bambusae Caulis in Taeniam as one of "Kun-Kings"}

Bamboo shavings, Zhu Ru/Bambusae Caulis in Taeniam $(\mathrm{BCT})$, medicinal herb in TEAM, is derived from the 


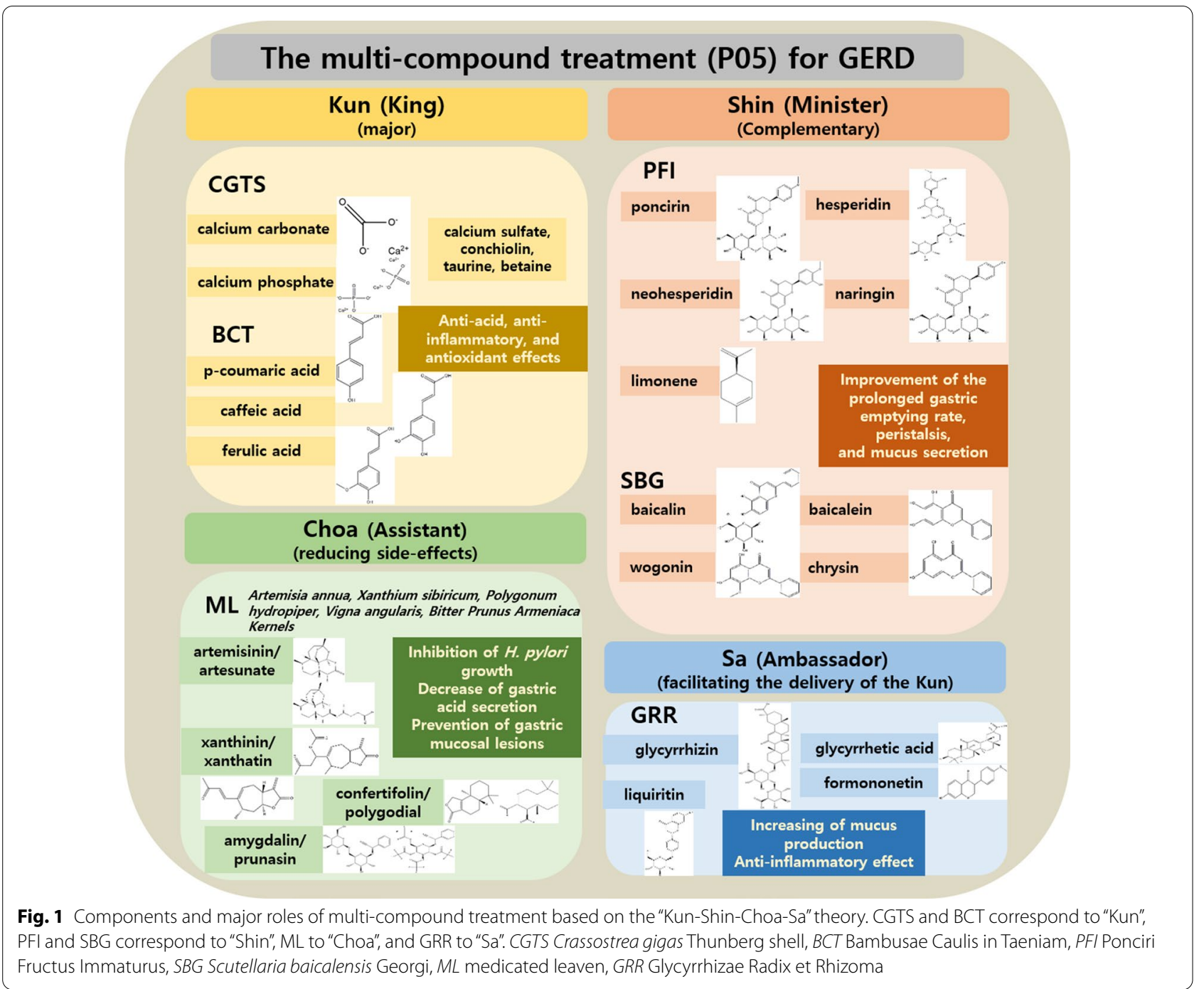

inner bark of Phyllostachys nigra var. henosis, and has been reported to have various pharmacological activities. It has been widely used to treat diarrhea, fever, and chest inflammation. A recent study indicated a beneficial effect on cigarette smoke-induced pulmonary and intestinal inflammation, asthma, and neurodegenerative diseases $[36,37]$. The major constituents of $\mathrm{BCT}$ are $p$-coumaric acid, which prevents oxidative gastric damage; caffeic acid, which has an anti-inflammatory effect on gastric mucosal damage via the nitric oxide (NO) pathway; ferulic acid, which decreases the total and free acidity of gastric contents [38-40]. A previous study pointed out that phenolic acids such as $p$-coumaric, caffeic, and ferulic acids play a significant role by displaying anti-secretory and effects, anti-histaminic effects, down-regulating parietal cell $\mathrm{H} \mathrm{p} / \mathrm{K}_{\mathrm{p}}$ adenosine triphosphatase, enhancing mucosal defensive factors, and cytoprotective effect by increasing the prostaglandin content and mucus formation in the gastric mucosa [38].

\section{Poncirus Fructus Immaturus as one of "Shin-Ministers"}

Poncirus immature fruit, Ponciri Fructus Immaturus (PFI), is the dried immature fruit of the trifoliate orange (Poncius trifoliate). It has been traditionally applied to treat diverse diseases, including ulcers, dyspepsia, constipation, gastritis, and several inflammation-associated ailments in TEAM [32]. A recent study also pointed out a beneficial effect against hyperlipidemia [33]. A growing body of evidence suggests the anti-inflammatory and gastroprotective effects of PFI [41]. The representative constituents of PFI are poncirin, which attenuates $\mathrm{HCI}$-induced gastric lesions; hesperidin, which improves the delayed gastric emptying rate; neohesperidin, which stimulates mucus secretion; naringin, which prevents 
Table 1 Bioactive components in an herbal mixture (P05) for GERD

\begin{tabular}{|c|c|c|c|c|c|}
\hline English name & Latin names & Main components & Chemical structure & $\begin{array}{l}\text { Primary mechanism of } \\
\text { action }\end{array}$ & References \\
\hline \multirow[t]{3}{*}{ Oyster shell } & $\begin{array}{l}\text { Crassostrea gigas Thunberg } \\
\text { shell }\end{array}$ & Calcium carbonate & $\mathrm{Ca}^{2+}$ & $\begin{array}{l}\text { Anti-acid } \\
\text { - Neutralization of esopha- } \\
\text { geal pH by increasing } \\
\text { plasma gastrin levels } \\
\text { - Inhibition of pepsin and } \\
\text { bile acid }\end{array}$ & {$[73,75,76]$} \\
\hline & & Calcium phosphate & $C$ & $\begin{array}{l}\text { Anti-acid } \\
\text { - The phosphate ions likely } \\
\text { react with hydrochloric } \\
\text { acid to neutralize the pH }\end{array}$ & {$[77,78]$} \\
\hline & & & $\left.\mathrm{Ca}^{2+}\right|_{\mathrm{O}} ^{\mathrm{P}}$ & & \\
\hline \multirow[t]{3}{*}{ Bamboo shavings } & $\begin{array}{l}\text { Bambusae Caulis in } \\
\text { Taeniam }\end{array}$ & $p$-Coumaric acid (p-CA) & $\mathrm{OH}$ & $\begin{array}{l}\text { Prevents oxidative gastric } \\
\text { damage by: } \\
\text { - Attenuating the ulcer- } \\
\text { elevated levels of malon- } \\
\text { dialdehyde } \\
\text { - Restoring the ulcer- } \\
\text { depleted levels of } \\
\text { reduced glutathione and } \\
\text { the antioxidant enzymes } \\
\text { such as superoxide } \\
\text { dismutase, catalase, glu- } \\
\text { tathione peroxidase, and } \\
\text { glutathione reductase }\end{array}$ & {$[38,79]$} \\
\hline & & Caffeic acid & & $\begin{array}{l}\text { - Attenuation of gastric } \\
\text { mucosal damage via the } \\
\text { NO pathway }\end{array}$ & {$[39,79]$} \\
\hline & & Ferulic acid & & $\begin{array}{l}\text { - Increase in gastric pH } \\
\text { - Decrease in total acidity, } \\
\text { free acidity, and lipid } \\
\text { peroxidation } \\
\text { - Inhibition of gastric acid } \\
\text { secretion by diminishing } \\
\mathrm{H}^{+}-\mathrm{K}^{+} \text {ATPase enzyme }\end{array}$ & {$[40,79]$} \\
\hline Poncirus immature fruit & Ponciri Fructus Immaturus & Poncirin & & $\begin{array}{l}\text { - Attenuation of HCl/ } \\
\text { ethanol-induced gastric } \\
\text { lesions } \\
\text { • Inhibition of iNOS, COX-2, } \\
\text { TNF-a, and IL-6 expres- } \\
\text { sion via the down-regu- } \\
\text { lation of NF-kB binding } \\
\text { activity }\end{array}$ & {$[52,53]$} \\
\hline
\end{tabular}


Table 1 (continued)

\begin{tabular}{|c|c|c|c|c|c|}
\hline English name & Latin names & Main components & Chemical structure & $\begin{array}{l}\text { Primary mechanism of } \\
\text { action }\end{array}$ & References \\
\hline & & Hesperidin & & $\begin{array}{l}\text { - Improvement of the } \\
\text { delayed gastric emptying } \\
\text { rate } \\
\text { - Inhibition of H. pylori } \\
\text { growth }\end{array}$ & {$[53,55]$} \\
\hline & & Neohesperidin & & $\begin{array}{l}\text { - Prevention of } \mathrm{HCl} / \text { ethanol- } \\
\text { induced gastric lesions } \\
\text { - Stimulation of mucus } \\
\text { secretion } \\
\text { - Increase in gastric pH } \\
\text { by decreasing in gastric } \\
\text { secretion and gastric acid } \\
\text { output }\end{array}$ & [53] \\
\hline & & Naringin & & $\begin{array}{l}\text { - Prevention of gastric ulcer } \\
\text { via inhibiting inflamma- } \\
\text { tion markers, including } \\
\text { TNF-a, IL-6, CRP, iNOS, and } \\
\text { caspase-3 levels }\end{array}$ & {$[80]$} \\
\hline & & Limonene & & $\begin{array}{l}\text { Neutralization of the gastric } \\
\text { acid effect by: } \\
\text { - Coating the stomach wall } \\
\text { - Protecting the mucosal } \\
\text { lining from gastric acid } \\
\text { exposure } \\
\text { - Improvement of healthy } \\
\text { peristalsis }\end{array}$ & {$[74]$} \\
\hline \multirow[t]{2}{*}{ Scutellariae root } & $\begin{array}{l}\text { Scutellaria baicalensis } \\
\text { Georgi }\end{array}$ & Baicalin & & $\begin{array}{l}\text { - Down-regulation of TRPV1 } \\
\text { in DRG neurons }\end{array}$ & {$[42,45]$} \\
\hline & & Baicalein & & $\begin{array}{l}\text { - Decrease of acute ulcers } \\
\text { via a2-adrenoreceptors, } \\
\text { SH compounds, NO, PG, } \\
\text { and KATP channels } \\
\text { - Increases in gastric mucus } \\
\text { secretion } \\
\text { - Inhibition of gastric acid } \\
\text { secretion by suppressing } \\
\text { the histaminergic path- } \\
\text { way and } \mathrm{H}^{+}, \mathrm{K}^{+} \text {-ATPase } \\
\text { activity }\end{array}$ & {$[43]$} \\
\hline
\end{tabular}


Table 1 (continued)

\begin{tabular}{|c|c|c|c|c|c|}
\hline English name & Latin names & Main components & Chemical structure & $\begin{array}{l}\text { Primary mechanism of } \\
\text { action }\end{array}$ & References \\
\hline & & Wogonin & & $\begin{array}{l}\text { - Anti-gastric inflammatory } \\
\text { agent via arachidonic } \\
\text { acid metabolism such as } \\
\text { induction of prostaglan- } \\
\text { din D2 and suppression } \\
\text { of } 5 \text { S-hydroxyeicosa- } \\
\text { tetraenoic acid (5S-HETE) } \\
\text { - Preventive induction of } \\
\text { profuse apoptosis in the } \\
\text { stomach }\end{array}$ & [44] \\
\hline & & Chrysin & & 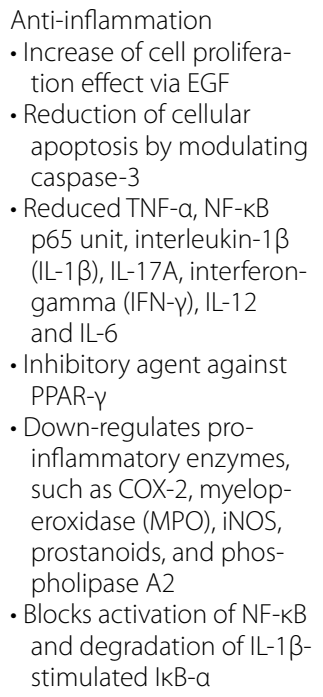 & {$[49,81]$} \\
\hline \multirow[t]{4}{*}{ Medicated leaven } & Artemisia annua & Artemisinin & & $\begin{array}{l}\text { - Inhibition of H. pylori } \\
\text { growth } \\
\text { - Suppression of H. pylori- } \\
\text { induced NF-kB activation }\end{array}$ & [54] \\
\hline & & Artesunate & & $\begin{array}{l}\text { - Decrease in gastric acid } \\
\text { secretion } \\
\text { - Inhibition of oxidative } \\
\text { stress markers such as } \\
\text { malondialdehyde, glu- } \\
\text { tathione, and superoxide } \\
\text { dismutase activity } \\
\text { - Reversing expression of } \\
\text { pro-inflammation mark- } \\
\text { ers, including TNF-a, IL-1 } \beta \text {, } \\
\text { IL-6, NF-KB, myeloperoxi- } \\
\text { dase, and COX-2 }\end{array}$ & {$[58,59]$} \\
\hline & Xanthium sibiricum & Xanthinin & & No previous research & \\
\hline & & Xanthatin & & $\begin{array}{l}\text { - Expressing anti-inflamma- } \\
\text { tion effect via suppres- } \\
\text { sion of NO production, } \\
\text { PGE2 synthesis, and 5- } \\
\text { lipoxygenase activity }\end{array}$ & {$[60,61]$} \\
\hline
\end{tabular}


Table 1 (continued)

\begin{tabular}{|c|c|c|c|c|c|}
\hline English name & Latin names & Main components & Chemical structure & $\begin{array}{l}\text { Primary mechanism of } \\
\text { action }\end{array}$ & References \\
\hline & Polygonum hydropiper & Confertifolin & & No previous research & \\
\hline & & Polygodial & & $\begin{array}{l}\text { - Prevention of gastric } \\
\text { mucosal lesions by } \\
\text { regulating endogenous } \\
\text { prostaglandins, NO, sulf- } \\
\text { hydryl compounds, and } \\
\text { vanilloid receptor }\end{array}$ & {$[82,83]$} \\
\hline & & (2E)-hexenal & & $\begin{array}{l}\text { - Inhibition of H. pylori } \\
\text { growth }\end{array}$ & {$[84]$} \\
\hline & & Isoquercetrin & & $\begin{array}{l}\text { Prevention of eosinophilic } \\
\text { esophagitis through a } \\
\text { decrease in eosinophil, } \\
\text { neutrophil, and IL-5 levels }\end{array}$ & [85] \\
\hline & Vigna angularis & Angularin & & $\begin{array}{l}\text { - Anti-inflammatory effects } \\
\text { through mitigation of NO } \\
\text { production }\end{array}$ & [54] \\
\hline & $\begin{array}{l}\text { Bitter Prunus armeniaca } \\
\text { Kernel }\end{array}$ & Amygdalin & & $\begin{array}{l}\text { - Inhibition of gastric ulcer } \\
\text { via diminishing NO } \\
\text { production and TNF-a } \\
\text { expression }\end{array}$ & [86] \\
\hline & & Prunasin & & $\begin{array}{l}\text { - Anti-inflammatory activity } \\
\text { via attenuation of IL-6, } \\
\text { IL-8, IL-23, HSP70 and } \\
\text { ICAM-1 expression }\end{array}$ & {$[57]$} \\
\hline
\end{tabular}


Table 1 (continued)

\begin{tabular}{|c|c|c|c|c|c|}
\hline English name & Latin names & Main components & Chemical structure & $\begin{array}{l}\text { Primary mechanism of } \\
\text { action }\end{array}$ & References \\
\hline \multirow[t]{5}{*}{ Licorice root } & $\begin{array}{l}\text { Glycyrrhizae Radix et } \\
\text { Rhizoma }\end{array}$ & Glycyrrhizin & & $\begin{array}{l}\text { - Expressing anti-inflam- } \\
\text { matory effect through } \\
\text { inhibiting the generation } \\
\text { of ROS by neutrophils }\end{array}$ & {$[57,58]$} \\
\hline & & Glycyrrhetic acid & & $\begin{array}{l}\text { - Inhibition of H. pylori } \\
\text { growth } \\
\text { • Inhibition of inflammatory } \\
\text { effect via attenuating } \\
\text { pro-inflammatory mark- } \\
\text { ers such as iNOS, COX-2, } \\
\text { TNF-a, IL-1 } \beta \text {, and IL-6 }\end{array}$ & {$[59,87]$} \\
\hline & & Liquiritin & & $\begin{array}{l}\text { - Anti-inflammatory effects } \\
\text { via attenuating pro- } \\
\text { inflammatory markers } \\
\text { such as iNOS, COX-2, } \\
\text { TNF-a, IL-1 } \beta \text {, and IL-6 }\end{array}$ & {$[87]$} \\
\hline & & Formononetin & & $\begin{array}{l}\text { - Decrease in gastric secre- } \\
\text { tion } \\
\text { - Increase in mucus produc- } \\
\text { tion }\end{array}$ & {$[60]$} \\
\hline & & Isoliquiritin & & $\begin{array}{l}\text { Antioxidant: } \\
\text { - Activation of Nrf2 pathway } \\
\text { Anti-inflammation: } \\
\text { - Suppression of NF-KB } \\
\text { pathway }\end{array}$ & {$[61]$} \\
\hline
\end{tabular}


gastric ulcers, and limonene, which enhances healthy peristalsis.

\section{Scutellaria baicalensis Georgi as one of "Shin-Ministers"} In TEAM, the root of Scutellariae, Scutellaria baicalensis Georgi (SBG), plays a significant role in clearing dampness and heat, resolving phlegm, purging fire, and detoxification.

SBG has been used for treating allergic and inflammatory diseases, and a variety of beneficial effects against cancer, psychiatric disorders, infectious and, circulatory diseases, among others, have been reported. In particular, concerning gastrointestinal (GI) diseases, it has been reported that baicalin has a treatment effect on $H$. pylori infection. At the same time, baicalein increases gastric mucus secretion, and wogonin acts as an anti-gastric inflammatory agent-these three constitute the major bioactive ingredients of SBG [42-45]. SBG has also been reported to be beneficial for improving liver fibrosis [46]. The representative constituents of SBG include baicalin, with an anti-inflammatory activity which occurs by communication with baicalein and oroxylin A via intestinal microflora through inhibiting NF- $\kappa$ B activation [47]; baicalein with antioxidant, anti-inflammatory, and anti-allergic effects and enhances intestinal barrier function [48]; wogonin, which has a gastric cytoprotective effect by enhancing $\mathrm{PGD}_{2}$ biosynthesis accompanied by decreased 5-HETE biosynthesis in alcohol-induced gastric mucosa injury and also has a strong anti-inflammatory effect [44]; chrysin, which has anti-inflammatory and antitoxic functions by inhibiting AGS human gastric cancer cell line growth $[49,50]$.

\section{Medicated leaven as a "Sa-Ambassador"}

Medicated leaven (ML) is a fermented mixture of wheat flour, Artemisia annua, Xanthium sibiricum, Polygonum hydropiper, Vigna angularis, and bitter Prunus armeniaca Kernel. ML, Shen qu, has been used to treat gastrointestinal (GI) diseases for thousands of years, such as reducing food stagnation, strengthening the stomach (stomach cold with food stagnation or accumulation, with epigastric and abdominal fullness or distention), lack of appetite, borborygmus, and diarrhea [51]. The primary components and related specific bioactive constituents of ML are described in the following sections.

\section{Artemisia annua-Artemisinin, Artesunate}

Artemisia annua inhibits $H$. pylori growth and decreases gastric acid secretion.

\section{Xanthium sibiricum-Xanthinin, xanthatin}

Xanthium sibiricum has been used to treat inflammation, pain, and infection, and traditionally known to dispel wind and dampness, detoxify, alleviate rheumatic pain [52].

Polygonum hydropiper-confertifolin, polygodial, (2E)-hexenal, isoquercitrin

Polygonum hydropiper is widely used as a traditional remedy for gastroenteritis and dysentery to eliminate phlegm, dampness, and inflammatory activity [53].

\section{Vigna angularis (adzuki bean)}

A previous study highlighted that angularin, the main component of Vigna angularis, has an anti-inflammatory effect by mitigating NO production [54].

\section{Bitter Prunus armeniaca Kernel (bitter apricot kernels)-Amygdalin, prunasin}

According to literature, the kernel of $P$. armeniaca L. has reported remarkable pharmacological effects such as strong antioxidant, antimicrobial, anti-inflammatory, anticancer, hepatoprotective, and cardioprotective activities [55].

\section{Glycyrrhizae Radix et Rhizoma as a "Choa-Assistant"}

Glycyrrhizae Radix et Rhizoma (GRR), licorice root, has diverse pharmacological activities, including antiviral, anti-inflammatory, anti-tumor, antimicrobial, anti-oxidative, anti-allergic, and hepatoprotective activities [56]. The primary components of GRR are glycyrrhizin, which has an anti-inflammatory effect by inhibiting the generation of ROS; glycyrrhetic acid, which inhibit $H$. pylori growth and inflammatory activity; liquiritin, with antiinflammatory effects; formononetin, which decreases gastric secretions and increases mucus production; isoliquiritin, with anti-inflammatory activity [42, 57-61].

\section{The results of network pharmacological analysis for P05}

We conducted a network pharmacological analysis to elucidate the system-level effects and mechanisms of P05. To investigate whether the targets of P05 are associated with GERD, hypergeometric tests were performed based on DisGeNET and HPO. Our results showed that the targets of P05 were statistically associated with GERD gene $\operatorname{sets}(p=0.0050)$, esophagitis $\left(p=2.3 \times 10^{-6}\right)$, and esophageal neoplasm $\left(p=7.6 \times 10^{-10}\right)$ (Table 2). These 
results indicate that the targets of P05 may be related to the pathophysiology of GERD and the GERD therapeutic effects.

Next, to explore the potential mechanisms of P05 in GERD, enrichment tests were conducted based on KEGG pathways. The pathways obtained from literature can be categorized into three groups: (1) pathways related to the digestive system: gastric acid secretion, epithelial cell signaling in $H$. pylori infection, pancreatic secretion, and bile secretion; (2) pathways related to cytokines, including TNF signaling pathway, IL-17 signaling pathway, inflammatory mediator regulation of TRP channels, NF- $\mathrm{kB}$ signaling pathway, and MAPK signaling pathway; and (3) pathways related to intrathoracic pressure: smallcell lung cancer, non-small cell lung cancer, tuberculosis, asthma, fatty acid degradation, and thermogenesis [62-65]. Figure 2 shows that P05 and its herbs were significantly associated with pathophysiologically important pathways. P05 is associated with all the digestive systemrelated pathways. Specifically, SBG and GRR are related to bile secretion and signaling in $H$. pylori infection, and $M L$ is simultaneously related to gastric acid secretion, indicating that P05 herbs complementarily affect the digestive system to control GERD. It also shows that P05 is related to multiple cytokine pathways, suggesting that P05 can alleviate esophagitis by modulating cytokine signaling pathways and that ML is significantly related to obesity-related pathways; otherwise, SBG, GRR, and $\mathrm{BCT}$ are related to respiratory diseases. These results indicate that P05 herbs can also modulate other diseases that aggravate GERD in a complementary manner. CGTS and PFI were not significantly related to these pathways.

To identify therapeutic compounds in P05 focused on digestive system-related pathways more directly involved in GERD, we isolated targets associated with digestive system-related pathways and visualized the herb-compound-target network. Among the pathways, the relationship between GERD and H. pylori is controversial: some argue that $H$. pylori infection can cause a decrease in gastric acid secretion and erosive esophagitis [66, 67], but others insist that there is no significant relationship between presence of $H$. pylori and prevalence or the symptom profiles of GERD $[68,69]$. In this study, we included the $H$. pylori-related pathway in network pharmacological analysis not to miss probable therapeutic mechanisms of P05 for GERD. As shown in Fig. 3, palmitic, hexanoic, and lauric acids, which are compounds of ML, and nobiletin, a PFI compound, are mainly associated with digestive fluid secretion, including bile, pancreatic, and gastric acid secretions. This finding corroborates the recognition of 'ML' and 'PFI' in traditional Asian medicine, as dyspepsia remedies. At the same time, several SBG and GRR compounds are related to signaling in $H$. pylori infection. Their targets, NFkB1, CASP3, and others, are associated with inflammation and the cell cycle, suggesting that SBG and GRR modulate cellular physiology in $H$. pylori infection. Of note is, baicalein, which is a well-known SBG compound, broadly affecting pathways linked to the digestive system, implying that baicalein itself modulates GERD's digestive system control. We noted that the targets of each herb are usually separated, supporting the notion that herbs in GERD can complimentarily affect digestive system-level pathology. Among these pathways, the relationship between GERD and $H$. pylori is controversial, some arguing that $H$. pylori infection can cause a decrease in gastric acid secretion and erosive esophagitis $[66,67]$. In contrast, others insist that there is no significant relationship between $H$. pylori and prevalence or the symptom profiles of GERD $[68,69]$. In the present study, we included the H. pylorirelated pathway to avoid omitting potential therapeutic mechanisms. In our results, CGTS and PFI were not significantly related to these pathways.

\section{Discussion}

The current review and network analysis revealed that the multi-compound treatment, $\mathrm{P} 05$, might be a potential therapeutic agent for GERD. The hypergeometric tests' results showed that the targets of P05 were significantly associated with GERD gene sets. This is consistent with the results of a review based on accumulated literature demonstrating that the herbal mixture, P05, prescribed based on the "Kun-Shin-Choa-Sa" theory, has comprehensive therapeutic effects on GERD. The major medicinal plants of the "Kun-Shin-Choa-Sa" theory-based P05 are Crassostrea gigas Thunberg shell (CGTS), Bambusae

Table 2 Enrichment analysis based on GERD gene sets and GERD-related diseases

\begin{tabular}{lllll}
\hline Diseases & $\begin{array}{l}\text { The number of } \\
\text { disease-related } \\
\text { genes }\end{array}$ & $\begin{array}{l}\text { The number of } \\
\text { targets of P05 }\end{array}$ & Overlap & $\begin{array}{l}\text { Adjusted } \\
\text { P-value }\end{array}$ \\
\hline GERD & 485 & 680 & 38 & 0.0050 \\
Esophagitis & 109 & 680 & 18 & $2.3 \times 10^{-6}$ \\
Esophageal neoplasms & 1185 & 680 & 108 & $7.6 \times 10^{-10}$ \\
\hline
\end{tabular}

GERD gastroesophageal reflux disease 


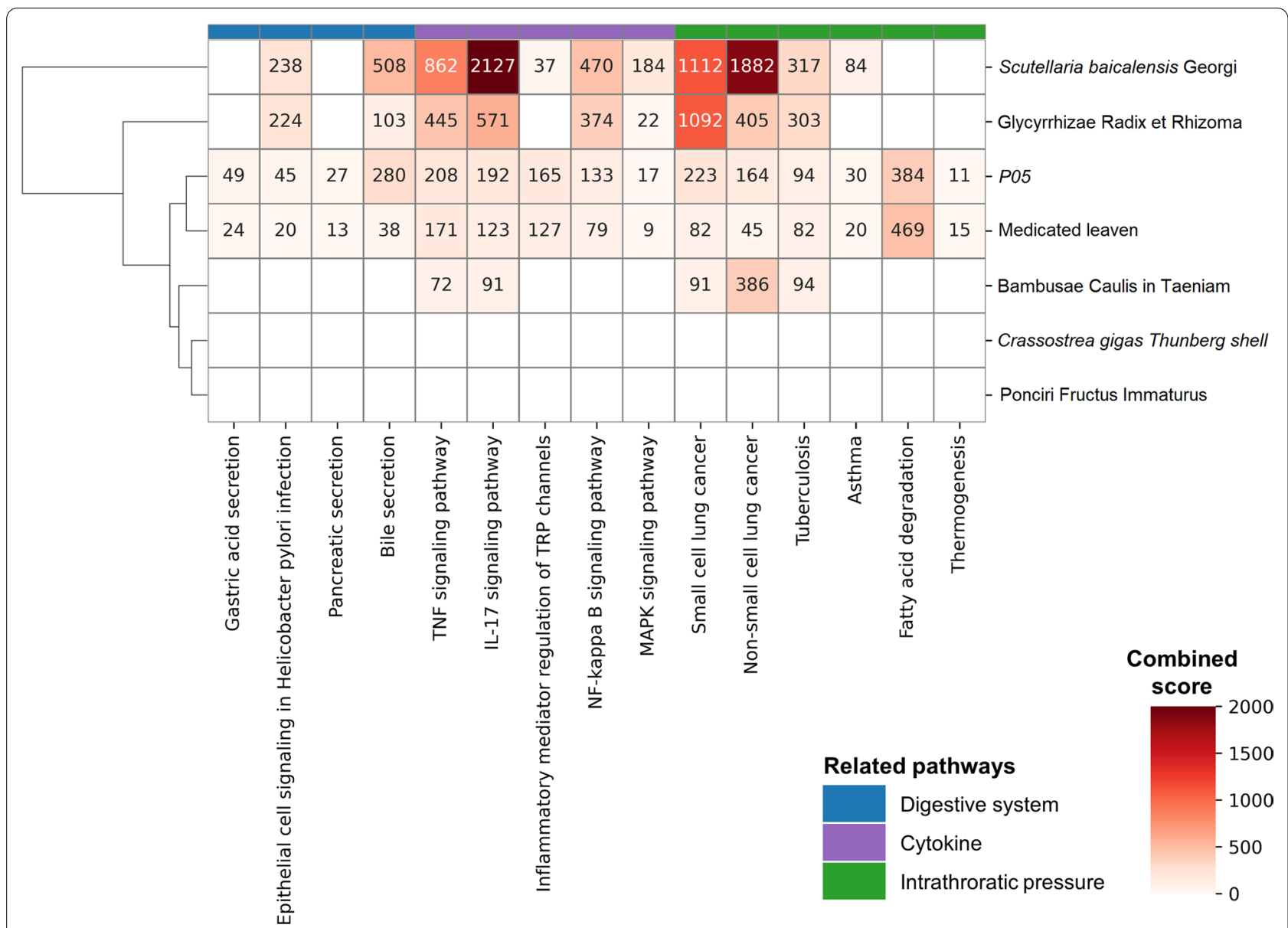

Fig. 2 Enrichment pathways associated with GERD by P05 targets and its constituent herbs. Colors of cells indicate combined scores that represent reliability of predicted associations between herbs and pathways. Colors of columns indicate categories of pathways. Combined scores with corresponding adjusted $p>0.05$ are masked

Caulis in Taeniam (BCT), Ponciri Fructus Immaturus (PFI), Scutellaria baicalensis Georgi (SBG), medicated leaven (ML), and Glycyrrhizae Radix et Rhizoma (GRR). Among the complex components of P05, CGTS and BCT play "Kun" role, whiles the roles of "Shin," "Choa," and "Sa" are fulfilled by PFI and SBG, ML, and GRR, respectively. P05 prescription emanates from diagnosis based on the TKM theory that phlegm, a significant pathological agent, is the primary cause of GERD. Zhu Zhenheng, a renowned TEAM practitioner from the Yuan dynasty, stated that nine out of ten diseases are caused by phlegm [70]. In TEAM, the dysfunction of fu organs that should send food down occurs due to phlegm, which leads to GERD as one of "damjeok syndrome" (damjeok means phlegm mass) [71]. P05 was prescribed based on the pathological diagnosis of GERD modified for modern individuals from Donguibogam. As a matter of course, the prescription will be changed in more detail by adding more medicinal herbs according to the specific symptoms and signs of the patients.

According to literature, two medicinal herbs, CGTS and $\mathrm{BCT}$, corresponding to "Kun-king," have medicinal components playing a strong role in decreasing gastric acidity and antioxidant and anti-inflammatory activities. Consistent with our findings, CGTS has been widely used as a food supplement for calcium supplementation in the body [72]. Previous studies have suggested that the calcium carbonate extracted from oyster shell transforms into calcium oxide, which can be used as an anti-acid agent [73]. Calcium carbonate is also efficiently absorbed by the intestine and helps improve bone mineral density in Japan's elderly population [74]. However, there was no significant association between CGTS and GERD-related pathways in the enrichment pathways analysis based on KEGG, which may be because CGTS mainly contains minerals such as calcium carbonate compared with other 


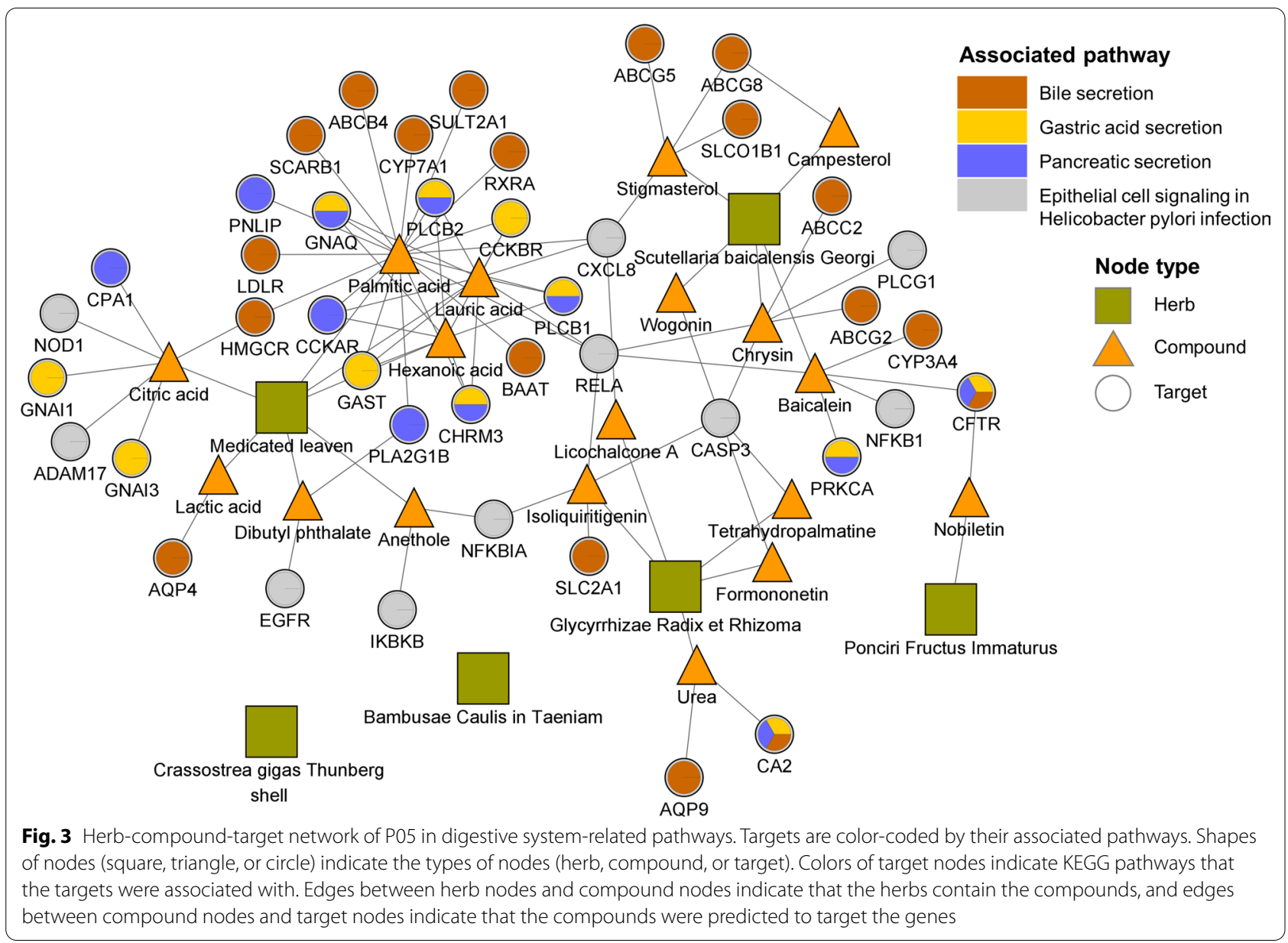

medicinal herbs. Several pathways are directly associated with GERD, including the gastric acid secretion pathway, epithelial cell signaling in the H. pylori pathway, pancreatic secretion pathway, bile secretion, and inflammation-related pathways. BCT is associated with cytokine signaling pathways, such as the TNF and IL-17 signaling pathways, which is consistent with the anti-inflammatory effect of BCT described in the current review.

The medicinal herbs equivalent to the "Shin-minister" that complement the "Kun" are PFI and SBG. Accumulating evidence points to the improvement of the delayed gastric emptying rate and peristalsis, attenuation of $\mathrm{HCI}$ induced gastric lesions, stimulation of mucus secretion, and a gastric cytoprotective effect of each of the PFI and SBG components. From the perspective of TKM, the fu organs, including the stomach, intestine, and bladder, are responsible for send foods down by peristalsis. Thus, GERD is thought to occur when the process of sending food down is disrupted by phlegm derived from the disharmony of body fluid. It is intriguing that the pathological diagnosis of GERD as a dysfunction of the digestion process, including the delayed gastric emptying rate in
TKM, is consistent with the efficacy of these medicinal herbs based on previous evidence. In contrast, PFI did not show a significant association with any pathway in the pathways enrichment analysis. This might be due to the lack of information regarding the mechanism of action of PFI and GERD-related pathways in the KEGG database, which requires further research. The enrichment analysis indicated that the targets of SBG, the other "Shin" component, are significantly associated with the IL-17 signaling pathway, bile secretion, respiratory pathways, including small-cell lung cancer and non-small cell lung cancer. The literature review indicated that SBG has anti-inflammatory and gastric cytoprotective effects. Taken together, the anti-inflammatory effect of SBG was shown in both the review findings and enrichment analysis.

Medicinal leaven (ML) consists of Artemisia annua, Xanthium sibiricum, Polygonum hydropiper, Vigna angularis, Bitter Prunus armeniaca kernels, which have been traditionally used for treating GI tract diseases for thousands of years. A recent study suggested that ML could be a new therapeutic agent for GI disorders due to its role 
in digestive function and its secondary metabolites, powerful antioxidant and anti-inflammatory activities [51]. ML assists "Kun" as "Choa" in P05 by ameliorating the side-effects of "Kun." According to literature, the ingredients in "Choa" have anti-inflammatory effects, reduce gastric acid secretion, and prevent GI mucosal damage, although it has not been established whether "Choa" is directly involved in reducing the side effects. Based on the pathway analysis, results indicated that ML mainly acts on gastric acid secretion, which is in accordance with the review findings. However, as shown in Fig. 3, the relationship between palmitic, hexanoic, and lauric acids in ML and digestive system-related pathways was not found in the literature review. Thus, further meticulous studies should be conducted to explore the relationship, and by extension, the differences between each ML component and the combined ML mixture's efficacy and underlying mechanisms.

The "Sa" that mediates "Kun's" efficacy in P05 is GRR, the most frequently used medicinal herb in TKM. In the enrichment analysis, the results implied that GRR is significantly related to epithelial cell signaling in the $H$. pylori infection pathway, bile secretion, inflammationrelated pathways such as the TNF signaling pathway, etc. This is consistent with the current review findings that the main components of GRR have an anti-inflammatory effect and increase mucus production.

Lastly, the integrated efficacy, safety, and the active mechanisms of the multi-compound herbal mixture (P05) and their roles from a "Kun-Shin-Choa-Sa" theory perspective should be investigated in the future through diverse designed studies such as in vitro, in vivo, and clinical trials.

This is the first study to review and analyze the mechanisms of action of the P05 multi-component herb mixture, Crassostrea gigas Thunberg shell (CGTS), Bambusae Caulis in Taeniam (BCT), Ponciri Fructus Immaturus (PFI), Scutellaria baicalensis Georgi (SBG), medicated leaven (ML), and Glycyrrhizae Radix et Rhizoma (GRR), for GERD treatment using network analysis. However, there are several limitations to this study. The specific extraction conditions of the herbal mixture and proportions of P05 components were not elucidated in this study because we were unable to obtain specific information on P05 from TKM practitioners. Future studies are required to explore the synergetic effects and unknown mechanisms of action of each herb in GERD treatment. In addition, the pharmacological mechanisms observed based on the network analysis should be experimentally verified via in vitro and in vivo studies. Furthermore, the P05 components we investigated should be considered in bioavailability and complex metabolic processes, as well as the pharmacological actions of metabolites. As seen in the literature review, each ingredient in P05 has not been equally studied. Some of herbal ingredients in P05 have been studied thoroughly, on the other hand, accumulated evidence for some herbal plants was scare. Therefore, there is a possibility that the findings on efficacy and relevance regarding each $\mathrm{P} 05$ component may be skewed according to the number of accumulated studies. This potential bias may also influence network pharmacological analysis using accumulated database based on existing research results. Lastly, even though natural products have been used since time immemorial, if any side effects of the natural herbs exist, even considerably weak side effects, they should be considered and dealt with.

\section{Abbreviations}

GERD: Gastroesophageal reflux disease; PPIs: Proton pump inhibitors; OTC: Over-the-counter; CAM: Complementary and alternative medicine; TKM: Traditional Korean medicine; TEAM: Traditional East Asian medicine; GI: Gastrointestinal; TLESR: Transient lower esophageal sphincter relaxation; LES: Lower esophageal sphincter; EGJ: Esophagogastric junction; H. pylori: Helicobacter pylori; CGTS: Crassostrea gigas Thunberg shell; BCT: Bambusae Caulis in Taeniam; PFI: Ponciri Fructus Immaturus; SBG: Scutellaria baicalensis Georgi; ML: Medicated leaven; GRR: Glycyrrhizae Radix et Rhizoma; NO pathway: Nitric oxide pathway.

\section{Acknowledgements}

Not applicable.

\section{Authors' contributions}

Conceptualization: S-HC and KSK; methodology, TJC, DJ and C-EK; investigation, JP and HMP; writing — original draft preparation, JP and DJ; writing review and editing, KSK; supervision, S-HC, SL, KSK; project administration, KSK. All authors have read and agreed to the published version of the manuscript. All authors read and approved the final manuscript.

\section{Funding}

This study was funded by National Research Foundation of Korea with Grant Number 2019R1F1A1059173 and Gachon University with Grant Number GCU-202002360001

\section{Availability of data and materials}

All data generated or analysed during this study are included in this published article [and its Additional files].

\section{Declarations}

Competing interests

The authors declare that they have no competing interests.

\section{Author details}

${ }^{1}$ College of Korean Medicine, Gachon University, Seongnam 13120, Republic of Korea. ${ }^{2}$ Wooje Research Institute for Integrative Medicine, WoojelM, Seoul 06200, Republic of Korea. ${ }^{3}$ Department of Oriental Internal Medicine, Weedahm Oriental Hospital, Seoul 06200, Republic of Korea. ${ }^{4}$ Department of Plant Science and Technology, Chung-Ang University, Anseong 17546, Republic of Korea. ${ }^{5}$ Department of Oriental Internal Medicine, Gangnam Weedahm Oriental Hospital, Seoul 06185, Republic of Korea.

Received: 30 March 2021 Accepted: 25 May 2021

Published online: 23 June 2021 


\section{References}

1. Loffeld RJ, van der Putten AB (2003) Rising incidence of reflux oesophagitis in patients undergoing upper gastrointestinal endoscopy. Digestion 68(2-3):141-144

2. Kang HS, Nam SW, Lee SE, Kwon HC, Park SM, Yang SU et al (2008) The prevalence of gastroesophageal reflux disease associated with age and body mass index in healthy Koreans. Ann Geriatr Med Res 12(4):201-206

3. Yang SY, Lee OY, Bak YT, Jun DW, Lee SP, Lee SH et al (2008) Prevalence of gastroesophageal reflux disease symptoms and uninvestigated dyspepsia in Korea: a population-based study. Dig Dis Sci 53(1):188-193

4. Cho YS, Choi MG, Jeong JJ, Chung WC, Lee IS, Kim SW et al (2005) Prevalence and clinical spectrum of gastroesophageal reflux: a populationbased study in Asan-si, Korea. Am J Gastroenterol 100(4):747-753

5. Gong EJ, Jung KW, Min YW, Hong KS, Jung HK, Son HJ et al (2019) Validation of the Korean version of the gastroesophageal reflux disease questionnaire for the diagnosis of gastroesophageal reflux disease. J Neurogastroenterol Motil 25(1):91-99

6. Aschenbrenner DS (2020) Ranitidine withdrawn from the market. AJN Am J Nurs 120(8):23

7. Song B-K, Won J-H, Kim S (2016) Historical medical value of Donguibogam. J Pharmacopunct 19(1):16-20

8. Wang Z, Okutsu K, Futagami T, Yoshizaki Y, Tamaki H, Maruyama T et al. Microbial community structure and chemical constituents in Shinkiku, a fermented crude drug used in Kampo Medicine. Front Nutr. 2020;7(115)

9. Gong J, Xia D, Huang J, Ge Q, Mao J, Liu S et al (2015) Functional components of bamboo shavings and bamboo leaf extracts and their antioxidant activities in vitro. J Med Food 18(4):453-459

10. Bickerton GR, Paolini GV, Besnard J, Muresan S, Hopkins AL (2012) Quantifying the chemical beauty of drugs. Nat Chem 4(2):90-98

11. Piñero J, Ramírez-Anguita JM, Saüch-Pitarch J, Ronzano F, Centeno E, Sanz F et al (2019) The DisGeNET knowledge platform for disease genomics: 2019 update. Nucleic Acids Res 48(D1):D845-D855

12. Köhler S, Vasilevsky NA, Engelstad M, Foster E, McMurry J, Aymé S et al (2017) The human phenotype ontology in 2017. Nucleic Acids Res 45(D1):D865-D876

13. Kuleshov MV, Jones MR, Rouillard AD, Fernandez NF, Duan Q, Wang Z et al (2016) Enrichr: a comprehensive gene set enrichment analysis web server 2016 update. Nucleic Acids Res 44(W1):W90-W97

14. Kanehisa M, Goto S (2000) KEGG: Kyoto encyclopedia of genes and genomes. Nucleic Acids Res 28(1):27-30

15. Hungin APS, Molloy-Bland M, Scarpignato C (2019) Revisiting Montreal: new insights into symptoms and their causes, and implications for the future of GERD. Am J Gastroenterol 114(3):414-21

16. Tack J, Becher A, Mulligan C, Johnson DA (2012) Systematic review: the burden of disruptive gastro-oesophageal reflux disease on health-related quality of life. Aliment Pharmacol Ther 35(11):1257-1266

17. Galmiche JP, Clouse RE, Bálint A, Cook IJ, Kahrilas PJ, Paterson WG et al (2006) Functional esophageal disorders. Gastroenterology 130(5):1459-1465

18. Malfertheiner P, Hallerbäck B (2005) Clinical manifestations and complications of gastroesophageal reflux disease (GERD). Int J Clin Pract 59(3):346-355

19. Herregods TVK, Bredenoord AJ, Smout AJPM (2015) Pathophysiology of gastroesophageal reflux disease: new understanding in a new era. Neurogastroenterol Motil 27(9):1202-1213

20. De Giorgi F, Palmiero M, Esposito I, Mosca F, Cuomo R (2006) Pathophysiology of gastro-oesophageal reflux disease. Acta Otorhinolaryngol Ital 26(5):241-246

21. Stengler M (2020) Risks of proton pump inhibitors for gastroesophageal reflux disease and a diet alternative. J Nutr Health Food Eng 10(1):1-3

22. Xie C, Wang J, Li Y, Tan N, Cui Y, Chen M et al (2017) Esophagogastric junction contractility integral reflect the anti-reflux barrier dysfunction in patients with gastroesophageal reflux disease. J Neurogastroenterol Motil 23(1):27-33

23. Han G, Leem J, Lee H, Lee J (2016) Electroacupuncture to treat gastroesophageal reflux disease: study protocol for a randomized controlled trial. Trials 17(1):246

24. Azzam RS (2018) Are the persistent symptoms to proton pump inhibitor therapy due to refractory gastroesophageal reflux disease or to other disorders? Arq Gastroenterol 55(Suppl 1):85-9
25. Fass R, Gasiorowska A (2008) Refractory GERD: what is it? Curr Gastroenterol Rep 10(3):252-257

26. Fossmark R, Martinsen TC, Waldum HL (2019) Adverse effects of proton pump inhibitors-evidence and plausibility. Int J Mol Sci 20(20):5203

27. Tarkang PA, Appiah-Opong R, Ofori MF, Ayong LS, Nyarko AK (2016) Application of multi-target phytotherapeutic concept in malaria drug discovery: a systems biology approach in biomarker identification. Biomark Res 4:25

28. Hao Y, Sun X, Zhang J (1998) Effects of Yunqitang on both esophageal mucosal morphology and esophageal motility in reflux esophagitis patients. Zhongguo Zhong xi yi jie he za zhi Zhongguo Zhongxiyi jiehe zazhi Chin J Integr Trad Western Med 18(6):345-347

29. Zhao L, Wang T, Dong J, Chen A, Li G (2018) Liver-stomach disharmony pattern: theoretical basis, identification and treatment. J Trad Chin Med Sci 5(1):53-57

30. Kim HU, Ryu JY, Lee JO, Lee SY (2015) A systems approach to traditional oriental medicine. Nat Biotechnol 33(3):264-268

31. Park J, Choi TJ, Kang KS, Choi S-H (2021) The interrelationships between intestinal permeability and phlegm syndrome and therapeutic potential of some medicinal herbs. Biomolecules 11(2):284

32. Shin EM, Zhou HY, Xu GH, Lee SH, Merfort I, Kim YS (2010) Anti-inflammatory activity of hispidol A 25-methyl ether, a triterpenoid isolated from Ponciri Immaturus Fructus. Eur J Pharmacol 627(1):318-324

33. Min DL, Park EJ (2015) The effects of Dai-saiko-to (Da-Chai-Hu-Tang) on 3T3-L1 preadipocytes and high-fat diet induced obeses mice. J Pediatr Korean Med 29(1):1-14

34. Lee SY, Kim HJ, Han JS (2013) Anti-inflammatory effect of oyster shell extract in LPS-stimulated raw 2647 cells. Prevent Nutr Food Sci. 18(1):23-29

35. Stenzel HB (1963) Aragonite and calcite as constituents of adult oyster shells. Science (New York, NY) 142(3589):232-233

36. Lim D, Cho Y, Kim W, Jeong S, Jang YP, Kim J (2017) Original research: extract of Bambusae Caulis in Taeniam inhibits cigarette smoke-induced pulmonary and intestinal inflammation. Exp Biol Med (Maywood) 242(1):102-112

37. Eom HW, Park SY, Kim YH, Seong SJ, Jin ML, Ryu EY et al (2012) Bambusae Caulis in Taeniam modulates neuroprotective and anti-neuroinflammatory effects in hippocampal and microglial cells via HO-1- and Nrf2-mediated pathways. Int J Mol Med 30(6):1512-1520

38. Panda V, Suresh S (2015) Gastro-protective effects of the phenolic acids of Macrotyloma uniflorum (horse gram) on experimental gastric ulcer models in rats. Food Biosci 12:34-46

39. Kolgazi M, Cilingir S, Yilmaz O, Gemici M, Yazar H, Ozer S et al (2021) Caffeic acid attenuates gastric mucosal damage induced by ethanol in rats via nitric oxide modulation. ChemBiol Interact. 334:109351

40. Umre R, Ganeshpurkar A, Ganeshpurkar A, Pandey S, Pandey V, Shrivastava A et al (2018) In vitro, in vivo and in silico antiulcer activity of ferulic acid. Fut J Pharmaceut Sci 4(2):248-253

41. Jeon W-Y, Kim OS, Seo C-S, Jin SE, Kim J-A, Shin H-K et al (2017) Inhibitory effects of Ponciri Fructus on testosterone-induced benign prostatic hyperplasia in rats. BMC Complement Altern Med 17(1):384

42. Yu X-D, Zheng R-B, Xie J-H, Su J-Y, Huang X-Q, Wang Y-H et al (2015) Biological evaluation and molecular docking of baicalin and scutellarin as Helicobacter pylori urease inhibitors. J Ethnopharmacol 162:69-78

43. Ribeiro AR, do Nascimento Valença JD, da Silva Santos J, Boeing T, da Silva LM, de Andrade SF et al (2016) The effects of baicalein on gastric mucosal ulcerations in mice: protective pathways and anti-secretory mechanisms. Chem Biol Interact 260:33-41

44. Park S, Hahm KB, Oh TY, Jin JH, Choue R (2004) Preventive effect of the flavonoid, wogonin, against ethanol-induced gastric mucosal damage in rats. Dig Dis Sci 49(3):384-394

45. Sui F, Zhang CB, Yang N, Li LF, Guo SY, Huo HR et al (2010) Anti-nociceptive mechanism of baicalin involved in intervention of TRPV1 in DRG neurons in vitro. J Ethnopharmacol 129(3):361-366

46. Chen HJ, Liang TM, Lee IJ, Huang YT, Lin YL (2013) Scutellariae radix suppresses LPS-induced liver endothelial cell activation and inhibits hepatic stellate cell migration. J Ethnopharmacol 150(3):835-842

47. Jung MA, Jang SE, Hong SW, Hana MJ, Kim DH (2012) The role of intestinal microflora in anti-inflammatory effect of baicalin in mice. Biomol Therapeut 20(1):36-42 
48. Bae M-J, Shin HS, See H-J, Jung SY, Kwon D-A, Shon D-H (2016) Baicalein induces CD4+Foxp3+T cells and enhances intestinal barrier function in a mouse model of food allergy. Sci Rep 6(1):32225

49. Naz S, Imran M, Rauf A, Orhan IE, Shariati MA, lahtisham UIH et al (2019) Chrysin: pharmacological and therapeutic properties. Life Sci 235:116797

50. Mohammadian F, Abhari A, Dariushnejad H, Nikanfar A, Pilehvar-Soltanahmadi Y, Zarghami N (2016) Effects of chrysin-PLGA-PEG nanoparticles on proliferation and gene expression of miRNAs in gastric cancer cell line. Iran J Cancer Prevent 9(4):e4190

51. Fu X, Wang Q, Kuang H, Pinghui J (2020) Mechanism of Chinese medicinal-medicated leaven for preventing and treating gastrointestinal tract diseases. Digestion 101(6):659-666

52. Yuan S-M (2020) Nutriology, pharmacology and cardiovascular effects of Xanthium sibiricum. Prog Nutr 22(2):370-377

53. Tao J, Wei Y, Hu T (2016) Flavonoids of Polygonum hydropiper L. attenuates lipopolysaccharide-induced inflammatory injury via suppressing phosphorylation in MAPKs pathways. BMC Complement Altern Med 16:25

54. Jiang Y, Zeng KW, David B, Massiot G (2014) Constituents of Vigna angularis and their in vitro anti-inflammatory activity. Phytochemistry 107:111-118

55. Hrichi S, Rigano F, Chaabane-Banaoues R, Oulad El Majdoub Y, Mangraviti D, Di Marco D et al (2020) Identification of fatty acid, lipid and polyphenol compounds from Prunus armeniaca L. Kernel extracts. Foods 9(7):896

56. Wang X-X, Liu G-Y, Yang Y-F, Wu X-W, Xu W, Yang X-W (2017) Intestinal absorption of triterpenoids and flavonoids from glycyrrhizae radix et rhizoma in the human Caco-2 monolayer cell model. Molecules 22(10):1627

57. Rahnama M, Mehrabani D, Japoni S, Edjtehadi M, Saberi FM (2013) The healing effect of licorice (Glycyrrhiza glabra) on Helicobacter pylori infected peptic ulcers. J Res Med Sci 18(6):532-533

58. Akamatsu H, Komura J, Asada Y, Niwa Y (1991) Mechanism of anti-inflammatory action of glycyrrhizin: effect on neutrophil functions including reactive oxygen species generation. Planta Med 57(2):119-121

59. Krausse R, Bielenberg J, Blaschek W, Ullmann U (2004) In vitro antiHelicobacter pylori activity of Extractum liquiritiae, glycyrrhizin and its metabolites. J Antimicrob Chemother 54(1):243-246

60. de Mendonça MAA, Ribeiro ARS, de Lima AK, Bezerra GB, Pinheiro MS, de Albuquerque-Júnior RLC et al (2020) Red propolis and its dyslipidemic regulator formononetin: evaluation of antioxidant activity and gastroprotective effects in rat model of gastric ulcer. Nutrients 12(10):2951

61. Liu Y, Xu X, Xu R, Zhang S (2019) Renoprotective effects of isoliquiritin against cationic bovine serum albumin-induced membranous glomerulonephritis in experimental rat model through its anti-oxidative and anti-inflammatory properties. Drug Des Dev Ther 13:3735-3751

62. Herbella FA, Patti MG (2010) Gastroesophageal reflux disease: from pathophysiology to treatment. World J Gastroenterol 16(30):3745-3749

63. Fass R (2003) Epidemiology and pathophysiology of symptomatic gastroesophageal reflux disease. Am J Gastroenterol 98(3 Suppl):S2-7

64. Altomare A, Guarino MP, Cocca S, Emerenziani S, Cicala M (2013) Gastroesophageal reflux disease: update on inflammation and symptom perception. World J Gastroenterol 19(39):6523-6528

65. Wu Y-W, Tseng P-H, Lee Y-C, Wang S-Y, Chiu H-M, Tu C-H et al (2014) Association of esophageal inflammation, obesity and gastroesophageal reflux disease: from FDG PET/CT perspective. PLOS ONE 9(3):e92001

66. El-Omar EM, Oien K, El-Nujumi A, Gillen D, Wirz A, Dahill S et al (1997) Helicobacter pylori infection and chronic gastric acid hyposecretion. Gastroenterology 113(1):15-24

67. Chung SJ, Lim SH, Choi J, Kim D, Kim YS, Park MJ et al (2011) Helicobacter pylori serology inversely correlated with the risk and severity of reflux esophagitis in Helicobacter pylori endemic area: a matched case-control study of 5,616 health check-up Koreans. J Neurogastroenterol Motil 17(3):267-273

68. Fallone CA, Barkun AN, Mayrand S, Wakil G, Friedman G, Szilagyi A et al (2004) There is no difference in the disease severity of gastro-oesophageal reflux disease between patients infected and not infected with Helicobacter pylori. Aliment Pharmacol Ther 20(7):761-768
69. Bor S, Kitapcioglu G, Kasap E (2017) Prevalence of gastroesophageal reflux disease in a country with a high occurrence of Helicobacter pylori. World J Gastroenterol 23(3):525-532

70. Kim H, Ku B, Kim JY, Park YJ, Park YB (2016) Confirmatory and exploratory factor analysis for validating the phlegm pattern questionnaire for healthy subjects. Evid Complement Altern Med eCAM 2016:2696019

71. Syndrome TSoPM. Available from: http://www.phlegmmass.or.kr/.

72. Silva HT, Mesquita-Guimarães J, Henriques B, Silva FS, Fredel MC (2019) The potential use of oyster shell waste in new value-added by-product. Resources 8(1):13

73. Fritz KTK, Parmar M (2020) Calcium carbonate. StatPearls Publishing

74. Fujita T, Fukase M, Miyamoto H, Matsumoto T, Ohue T (1990) Increase of bone mineral density by calcium supplement with oyster shell electrolysate. Bone Miner 11(1):85-91

75. Decktor DL, Robinson M, Maton PN, Lanza FL, Gottlieb S (1995) Effects of aluminum/magnesium hydroxide and calcium carbonate on esophageal and gastric $\mathrm{pH}$ in subjects with heartburn. Am J Ther 2(8):546-552

76. Weberg R, Berstad A (1989) Symptomatic effect of a low-dose antacid regimen in reflux oesophagitis. Scand J Gastroenterol 24(4):401-406

77. Dorozhkin SV, Epple M (2002) Biological and medical significance of calcium phosphates. Angew Chem Int Ed 41(17):3130-3146

78. Windholz M, Budavari S, Stroumtsos LY, Fertig MN. The Merck index. An encyclopedia of chemicals and drugs. 1976. English.

79. Kim W, Lim D, Kim J (2018) p-Coumaric acid, a major active compound of Bambusae Caulis in Taeniam, suppresses cigarette smoke-induced pulmonary inflammation. Am J Chin Med 46(02):407-421

80. Gomaa EZ (2013) In vitro antioxidant, antimicrobial, and antitumor activities of bitter almond and sweet apricot (Prunus armeniaca L.) kernels. Food Sci Biotechnol 22(2):455-463

81. Fagundes FL, Piffer GDM, Périco LL, Rodrigues VP, Hiruma-Lima CA, Santos RDCD (2020) Chrysin modulates genes related to inflammation, tissue remodeling, and cell proliferation in the gastric ulcer healing. Int J Mol Sci 21(3):760

82. Matsuda H, Pongpiriyadacha Y, Morikawa T, Kashima Y, Nakano K, Yoshikawa M (2002) Protective effects of polygodial and related compounds on ethanol-induced gastric mucosal lesions in rats: structural requirements and mode of action. Bioorg Med Chem Lett 12(3):477-482

83. Pongpiriyadacha Y, Matsuda H, Morikawa T, Asao Y, Yoshikawa M (2003) Protective effects of polygodial on gastric mucosal lesions induced by necrotizing agents in rats and the possible mechanisms of action. Biol Pharm Bull 26(5):651-657

84. Kubo I, Fujita K-I, Kubo A, Nihei K-I, Ogura T (2004) Antibacterial activity of coriander volatile compounds against Salmonella choleraesuis. J Agric Food Chem 52(11):3329-3332

85. Rogerio AP, Kanashiro A, Fontanari C, da Silva EV, Lucisano-Valim YM, Soares EG et al (2007) Anti-inflammatory activity of quercetin and isoquercitrin in experimental murine allergic asthma. Inflam Res Off J Eur Histamine Res Soc 56(10):402-408

86. Nabavizadeh F, Alizadeh AM, Saderoleslami Z, Adeli S (2011) Gastroprotective effects of amygdalin on experimental gastric ulcer: role of $\mathrm{NO}$ and TNF-a. J Med Plants Res 5(14):3122-3127

87. Yu JY, Ha JY, Kim KM, Jung YS, Jung JC, Oh S (2015) Anti-Inflammatory activities of licorice extract and its active compounds, glycyrrhizic acid, liquiritin and liquiritigenin, in BV2 cells and mice liver. Molecules 20(7):13041-13054

\section{Publisher's Note}

Springer Nature remains neutral with regard to jurisdictional claims in published maps and institutional affiliations. 